\title{
Use of a recombinase polymerase amplification commercial kit for rapid visual detection of Pasteurella multocida
}

\author{
Guimin Zhao, Hongbin He ${ }^{*}$ and Hongmei Wang ${ }^{*}$ (D)
}

\begin{abstract}
Background: Pasteurella multocida (P. multocida) is a bacterium that causes bovine respiratory disease (BRD) and haemorrhagic septicaemia (HS) in cattle, buffaloes and bison. Rapid point-of-care diagnosis or regular testing of Pasteurellosis, therefore, could contribute greatly to early detection, and screening infected animal is important. Up to now, there are no published reports on the use of recombinase polymerase amplification (RPA) combined with a lateral flow dipstick (LFD) for $P$. multocida detection.

Results: This study proposes a promising isothermal detection method for $P$. multocida with the potential to be developed as an on-site test for Pasteurellosis. The method includes an RPA combined with LFD. First, the analytical sensitivity and specificity of $P$. multocida RPA-LFD were tested. The RPA-LFD, performed at $39^{\circ} \mathrm{C}$, successfully detected P. multocida DNA in 30 min, with a detection limit of up to 120 copies per reaction. Then, the practicability of RPA-LFD was analysed using 62 nasal swabs and 33 fresh lungs samples from 17 different dairy farms. Compared to real-time quantitative PCR (qPCR), the RPA-LFD assay yielded a clinical specificity of 95.15\%, positive predictive value (PPV) of 95.15\% and 0.958 kappa coefficient. Compared with the culture method, it achieved 100\% sensitivity, 67.20\% specificity and a 0.572 kappa coefficient.

Conclusions: These results combined with the simple conditions required for the performance of the RPA-LFD assay, have demonstrated the effectiveness and practicability of the method for development into a regular on-site protocol for the diagnosis of Pasteurellosis.
\end{abstract}

Keywords: Recombinase polymerase amplification, Pasteurella multocida, Lateral flow dipstick

\section{Background}

Pasteurella multocida (P. multocida) is a pathogenic gram-negative bacterium that plays a role in multihost diseases [1]. P. multocida has been identified in shipping fever of weaned calves and in enzootic neonatal calf pneumonia [2]. It also cause heamorrhagic septicaemia (HS), a disease normally found in some areas of Asia, Africa, the Middle East and southern Europe in cattle, buffaloes and bison [3]. Epidemic outbreaks of these diseases can cause serious economic losses in related industries. Development of a quick, exact field diagnostic test

\footnotetext{
* Correspondence: hongbinhe@sdnu.edu.cn; hongmeiwang@sdnu.edu.cn Ruminant Disease Research Center, Key Laboratory of Animal Resistant Biology of Shandong, College of Life Science, Shandong Normal University, No.88 Wenhua East Road, Lixia District, Jinan 250014, Shandong Province, China
}

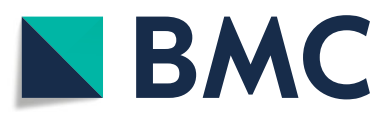

(๑) The Author(s). 2019 Open Access This article is distributed under the terms of the Creative Commons Attribution 4.0 International License (http://creativecommons.org/licenses/by/4.0/), which permits unrestricted use, distribution, and reproduction in any medium, provided you give appropriate credit to the original author(s) and the source, provide a link to the Creative Commons license, and indicate if changes were made. The Creative Commons Public Domain Dedication waiver (http://creativecommons.org/publicdomain/zero/1.0/) applies to the data made available in this article, unless otherwise stated. for the prevention and control of Pasteurellosis.

At present, nucleic acid amplification technologies (NAAT) are often used in rapid diagnostic tests of infectious diseases. However, most nucleic acid detection technologies with usable sensitivity and accuracy, such as PCR and real-time quantitative PCR (qPCR), require fully equipped stationary laboratories and complex thermal cycling instruments. In addition, most NAAT assays, including a number of isothermal amplification techniques, need power-dependent instruments to provide thermal energy. The reaction time is about $2 \mathrm{~h}$, which is quite time-consuming [4].

Since the first report in 2006, isothermal recombinase polymerase amplification (RPA) nucleic acid amplification technology has been acknowledged for its advantages including rapidity and simplicity $[5,6]$. The combination of 
the RPA assay and a lateral flow dipstick (LFD) is specially suitable for on-site detection of clinical samples. RPA can tolerate temperatures from 30 to $45^{\circ} \mathrm{C}$ but does not lose its response efficiency. It has been successfully used for rapid, sensitive and visual detection of bovine rhinotracheitis virus, foot-and-mouth disease virus and Mycoplasma bovis in cattle $[5,7,8]$. In this paper, we established an RPA-LFD assay targeting a previously identified conserved gene of P. multocida: the Kmt1 gene [9]. Additionally, we estimated the specificity, sensitivity and clinical application of the RPA-LFD assay in comparison with qPCR and culture methods to assess its practicality and performance as a potential on-site field test.

\section{Results}

Determination of RPA-LFD conditions

First, the analytical specificity of three different combinations of RPA primers and an LF-probe was determined using $6 \times 10^{4}$ copies/ $\mu$ l of standard DNA by agarose-gel electrophoresis (AGE). Two bands were clearly observed by electrophoresis (Fig. 1a). Various primer combinations and targets were evaluated and one primer pair, F2: 5' -TTGCCGCGAAATTGAGTTTTATGCCACTTG-3' and R: 5'-Biotin-AATAACGTCCAATCAGTTGCGCC GTTGTCA-3', yielded highest amplification accuracy and was selected during the process, resulting in an amplicon with a size of 189 bp targeting a region on the $K m t 1$ gene

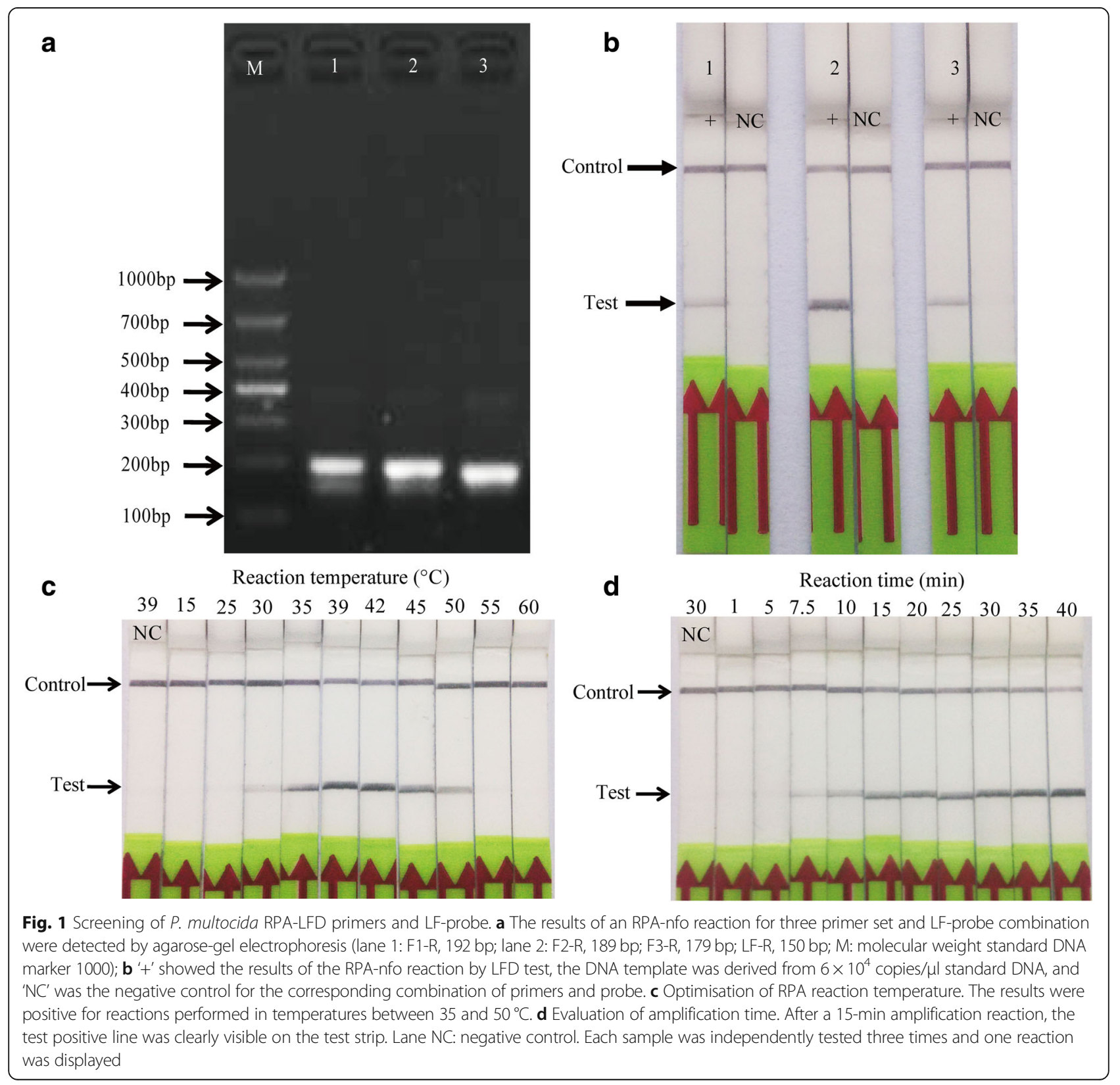


of P. multocida (Fig. 1a). This primer set also produced a faster and darker positive line than the other two groups within $5 \mathrm{~min}$, while no band was noticeable in the negative control (Fig. 1b).

The preferred temperature and time for the RPA reaction were also evaluated. A reaction temperature range of $15-60^{\circ} \mathrm{C}$ and a reaction time range of $1-40$ min were screened using $6 \times 10^{4}$ copies of plasmid DNA as template. The results showed that the RPA reaction adapted to a broad temperature range of $30-50^{\circ} \mathrm{C}$, and the test band was brightest between 39 and $42^{\circ} \mathrm{C}$ (Fig. 1c). Therefore, $39^{\circ} \mathrm{C}$ was selected as the optimum reaction temperature in subsequent RPA-LFD testing. Regarding the incubation time, obvious bands were seen at the location of the test area within the range of $15-40 \mathrm{~min}$. However, the band was very weak from $7.5 \mathrm{~min}$ to 10 min (Fig. 1d). According to the results, an amplification time of $30 \mathrm{~min}$ was selected for all subsequent RPA-LFD assays.

\section{Sensitivity and specificity of the RPA-LFD assay}

The analytical sensitivity of the $P$. multocida RPA-LFD assay was confirmed using 10-fold serially diluted standard DNA $\left(6 \times 10^{7}\right.$ to 6 copies/ $\left.\mu l\right)$. The result revealed that the established RPA-LFD assay had a similar molecular sensitivity to that of the qPCR assay with a limit of detection of up to 120 copies per reaction (Fig. 2 and Table 1). Next, the analytical specificity of the RPA-LFD was tested using members of the family Pasteurellaceae and other important bacterial pathogens of cattle which cause similar clinical signs (Table 2). It was determined that no cross-amplification was observed against other pathogens (data not shown). These results indicated that the $P$. multocida RPA-LFD assay was specific for detection of $P$. multocida.

\section{Performance of RPA-LFD assay on clinical samples}

Finally, the practicality and efficiency of the RPA-LFD were compared to those of the qPCR and culture methods. The result showed that RPA-LFD had a similar positive rate compared with that of the $\mathrm{qPCR}$ assay [positive rate of $54.74 \%(52 / 95)$ and $52.63 \%$ (50/95), respectively (Table 3)]. However, the positive rate of isolated P. multocida was lower than that of the RPA-LFD assay in the 95 clinical samples [positive rate of $32.63 \%$ $(31 / 95)$ and $54.74 \%(52 / 95)$, respectively (Table 3$)]$. The optimized RPA-LFD assay achieved $67.20 \%$ specificity, $59.62 \%$ positive predictive value (PPV) and a 0.572 kappa coefficient when compared with the bacterial isolation culture method (Table 4). To confirm whether or not the system amplified the correct target, the amplicons of the samples that tested positive in the RPA-LFD assay but negative in the culture or GPCR method were purified and further sequenced. The amplification region of a 189-nucleotide were $100 \%$ consistent with that of $P$. multocida Kmt1 gene, which proved the accuracy of the RPA-LFD assay.

\section{Discussion}

P. multocida has been isolated from a number of different species, is potentially zoonotic $[10,11]$ and has been associated with many different diseases, including BRD. BRD can result in significant economic loss to cattle herds both locally and internationally [12]. P. multocida is an extraordinary important pathogen in BRD and has been associated with this disease since the early 1950s [10]. Nevertheless, although an opportunistic role is assumed for this pathogen, many virulence factors and the prevalence of BRD co-infections are recognized [10]. Thus, a robust diagnostic assay capable of rapid, specific and sensitive detection of $P$. multocida in a feedlot or cow-calf operation could play a significant role in reducing the shipping fever of weaned calves and calf pneumonia-related morbidity and mortality, particularly in developing countries.

In this paper we have confirmed the application of RPA-LFD to diagnose Pasteurellosis from clinical samples.
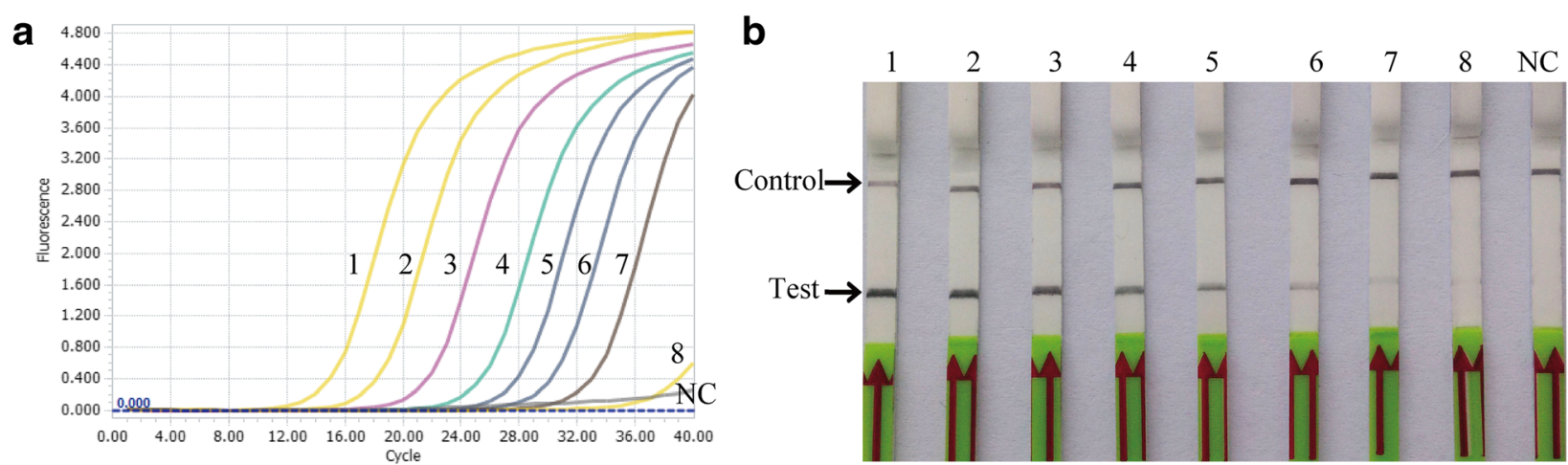

Fig. 2 Detection of 10-fold serially diluted P. multocida standard DNA by RPA-LFD and qPCR assays. a qPCR results. b RPA-LFD results. Lane 1 to 8: 10 -fold serially diluted $P$. multocida standard DNA from $6 \times 10^{7}$ to 6 copies/ $\mu$ l. Lane NC: negative control. Each sample was independently tested three times and one reaction was displayed 
Table 1 Assay detection results from P. multocida plasmid DNA standards

\begin{tabular}{|c|c|c|c|c|c|c|c|}
\hline \multirow[t]{2}{*}{ Number } & \multirow{2}{*}{$\begin{array}{l}\text { DNA standards } \\
\text { (copies/ } \mu \mathrm{l})\end{array}$} & \multicolumn{3}{|c|}{ Real-time qPCR } & \multicolumn{3}{|c|}{ RPA-LFD } \\
\hline & & Ct 1 & Ct 2 & $\mathrm{Ct} 3$ & Test 1 & Test 2 & Test 3 \\
\hline 1 & $60,000,000$ & 13.82 & 13.95 & 13.92 & + & + & + \\
\hline 2 & 6000,000 & 17.15 & 17.18 & 17.23 & + & + & + \\
\hline 3 & 600,000 & 20.12 & 20.36 & 20.43 & + & + & + \\
\hline 4 & 60,000 & 23.92 & 23.56 & 23.29 & + & + & + \\
\hline 5 & 6000 & 26.81 & 27.07 & 26.31 & + & + & + \\
\hline 6 & 600 & 28.19 & 28.1 & 28.22 & + & + & + \\
\hline 7 & 60 & 31.47 & 31.86 & 31.09 & + & + & + \\
\hline 8 & 6 & 40.00 & 40.00 & 39.07 & - & - & + \\
\hline 9 & NC & 40.00 & 40.00 & 40.00 & - & - & - \\
\hline
\end{tabular}

Ct threshold cycle, $N C$ negative control

An RPA-LFD assay targeting the Kmt1 gene was examined and demonstrated the ability to detect $P$. multocida DNA with a high degree of specificity and sensitivity in less than $30 \mathrm{~min}$. The sensitivity indicated that the RPA-LFD assay had a similar detection limit to that of the qPCR method (Fig. 2 and Table 1). Furthermore, analytical specificity showed that the assay could detect five distinct capsular serogroups, but detection of common pathogens in infected cattle was negative (Table 2).

To confirm the diagnostic practicality of the P.multocida RPA-LFD assay, the same clinical sample $(n=95)$ set was evaluated by the qPCR assay, and result produced 0.958 kappa coefficient with qPCR (Table 4). However, the positive rate for isolation of $P$. multocida was lower than RPA-LFD assay in 95 clinical samples, [positive rate of $32.63 \%$ (31/95) and $54.74 \%$ (52/95), respectively]. The results showed that the culture method also had a lower clinical sensitivity than qPCR and RPA-LFD assays. In addition, previous antibiotic treatment of diseased animals may hinder bacterial isolation [13].

The RPA-LFD assay has the following merits: rapidity: RPA amplification and LFD detection can be finished within 30-40 min; isothermal amplification: operates at a lower temperature of $39^{\circ} \mathrm{C}$; and economical value: lower dependence on heat cycle instrument and professional operations. Combined with laboratory-independent nucleic acid purification technology, the RPA-LFD assay may be used as an alternative on-site diagnostic test in lowresource conditions [14, 15], since a simple heating system, such as water bath, chemical heater or even body heat could be used for the majority of the reaction [14-16]. Admittedly, the development of simplified DNA template preparation ( $\mathrm{NaOH}$-based DNA extraction) would further increase the potential for the wide utilization of this method [17]. Partial simulations of field conditions have provided evidence for the coming
Table 2 Bacterial strains used to test RPA-LFD assay specificity

\begin{tabular}{|c|c|c|c|}
\hline Number & Species & Strains/origin & RPA-LFD \\
\hline 1 & Pasteurella multocida (A) & BNCC126487ª & Positive \\
\hline 2 & Pasteurella multocida (A) JN14 & Clinical separation ${ }^{\mathrm{b}}$ & Positive \\
\hline 3 & Pasteurella multocida (A) TJ14 & Clinical separation ${ }^{\mathrm{b}}$ & Positive \\
\hline 4 & Pasteurella multocida (A) JN15 & Clinical separation ${ }^{\mathrm{b}}$ & Positive \\
\hline 5 & Pasteurella multocida (B) & BNCC126234 & Positive \\
\hline 6 & Pasteurella multocida (B) TJ16 & Clinical separation ${ }^{\mathrm{b}}$ & Positive \\
\hline 7 & Pasteurella multocida (D) & $\operatorname{CVCC}_{392}{ }^{c}$ & Positive \\
\hline 8 & Pasteurella multocida (E) & CVCC393 & Positive \\
\hline 9 & Pasteurella multocida (F) & CVCC394 & Positive \\
\hline 10 & Pasteurella avium & BNCC128728 & Negat \\
\hline 11 & Pasteurella gallinarum & BNCC131586 & Negati \\
\hline 12 & Pasteurella trehalosi & TCCPTA- $3668^{\mathrm{a}}$ & $\mathrm{Neg}$ \\
\hline 13 & Pasteurella stomatis & ATCC $43327^{\mathrm{a}}$ & Negat \\
\hline 14 & Pasteurella langaa & ATCC $43328^{\mathrm{a}}$ & Neg \\
\hline 15 & Pasteurella dagmatis & ATCC51570 & Negati \\
\hline 16 & $\begin{array}{l}\text { Actinobacillus } \\
\text { pleuropneumoniae }\end{array}$ & BNCC129808 & Negat \\
\hline 17 & Mycoplasma bovis PG45 & ATCC25523a & $\mathrm{Nec}$ \\
\hline 18 & $\begin{array}{l}\text { Mycoplasma mycoides } \\
\text { subsp. mycoides }\end{array}$ & BNCC126186 & Negat \\
\hline 19 & Mannheimia haemolytica & BNCC128674 & Negat \\
\hline 20 & Trueperella pyogenes & Clinical separation ${ }^{\mathrm{b}}$ & Negati \\
\hline 21 & Histophilus somni & Clinical separation ${ }^{\mathrm{b}}$ & Negati \\
\hline 22 & Klebsiella pneumoniae & BNCC194477 ${ }^{a}$ & Neg \\
\hline 23 & Proteus mirabilis & BNCC107943 ${ }^{\mathrm{a}}$ & Negati \\
\hline 24 & Streptococcus bovis & ATCC $33317^{\mathrm{a}}$ & Negati \\
\hline 25 & Staphylococcus aureus & ATCC6538P & Negativ \\
\hline 26 & Escherichia coli O157:H7 & BNCC $186579^{a}$ & Negat \\
\hline 27 & Pseudomonas aeruginosa & Clinical separation ${ }^{\mathrm{b}}$ & Negati \\
\hline 28 & Salmonella typhimurium & BNCC108207 & Neg \\
\hline 29 & Enterococcus faecalis & ATCC29212 & Neg \\
\hline 30 & Bacillus cereus & BNCC103930 a & Negat \\
\hline
\end{tabular}

${ }^{a}$ These strains were provided from BNCC; ${ }^{\mathrm{b}}$ These strains were preserved in our laboratory; ${ }^{\circ}$ These strains were provided from CVCC

potential of the RPA-LFD assay as a sensitive, quick, and accurate field test for detection of $P$. multocida.

\section{Conclusions}

In summary, the RPA-LFD was successfully applied for the detection of $P$. multocida. For the amplification reaction, only a water bath at $39^{\circ} \mathrm{C}$ was needed, and amplicons analysis was simply carried out on the LFD. We have provided an evidence base for RPA-LFD as a tool for the sensitive, simple, and rapid detection of DNA from $P$. multocida, which potentially could be applied in 
Table 3 Comparison of the P. multocida RPA-LFD, real-time qPCR and culture methods on clinical samples

\begin{tabular}{|c|c|c|c|c|c|c|c|}
\hline \multirow[t]{2}{*}{ Samples type } & \multirow{2}{*}{$\begin{array}{l}\text { Number of } \\
\text { samples }\end{array}$} & \multicolumn{2}{|l|}{ RPA-LFD } & \multicolumn{2}{|c|}{ Real-time qPCR } & \multicolumn{2}{|l|}{ Culture } \\
\hline & & Positive & Negative & Positive & Negative & Positive & Negative \\
\hline Nasal swabs & 62 & 29 & 33 & 27 & 35 & 18 & 44 \\
\hline Fresh lungs & 33 & 23 & 10 & 23 & 10 & 13 & 20 \\
\hline Total & 95 & 52 & 43 & 50 & 45 & 31 & 64 \\
\hline
\end{tabular}

clinical diagnosis and the molecular epidemiologic investigation of $P$. multocida infection.

\section{Methods}

\section{Bacterial strains}

P. multocida reference strains from serogroup A and B (Table 2) used in this study were provided from the BeNa Culture Collection (BNCC, China). Three capsular serogroups (D, E, and F) of $P$. multocida reference strains were provided from China Veterinary Culture Collection Center (CVCC, China). A total of 4 isolates of $P$. multocida previously isolated from cattle and goat and maintained at the Ruminant Disease Research Center, Shandong Normal University, Shandong Province, China, were used in this study. For the purpose of testing the detection specificity, members of the family Pasteurellaceae and other important bacterial pathogens of cattle which cause similar clinical signs (Table 2) were preserved in our lab or purchased from BNCC and employed.

\section{Clinical samples}

A total of 95 clinical samples, including nasal swabs $(n=62)$ and fresh lung tissue of calves $(n=33)$, were collected from cattle with BRD on 17 different dairy farms located in 17 distinct geographic regions of Shandong province $[18,19]$ in China between January 2017 and February 2018 [20]. Samples were plated onto blood agar (5\% fresh sheep blood) with a disposable sterile loop and incubated at $37^{\circ} \mathrm{C}$ in air for a minimum of $48 \mathrm{~h}$. All presumptive colonies of cultured $P$. multocida were further confirmed by PCR assay with primers specifically designed for the amplification of the
Kmt1 gene [9, 21]. DNA was extracted from the colonies and clinical samples by using the TIANamp bacteria DNA kit or swab DNA kit (Tiangen Biotech, China) according to the manufacturer's instructions [5]. DNA was stored at $-20^{\circ} \mathrm{C}$ until $P$. multocida detection could be performed.

\section{Design of RPA primer and LF-probe}

Three combinations of candidate primers ( 3 forward and one reverse) and one TwistAmp LF-probe (a 3' blocker and an internal abasic site that replaces a nucleotide) were designed based on the sequence of $K m t 1$ gene of $P$. multocida (nucleotides 249 to 440 of the GenBank accession number: AF016259.1) (Fig. 3 and Table 5). Synthesis was performed by TsingKe Biological Technology (Beijing, China).

\section{RPA-nfo reaction and optimisation}

RPA-nfo reaction was carried out in a $50 \mu \mathrm{l}$ volume using a ready-made TwistAmp nfo kit (TwistDX, UK) $[5,22]$. For each sample, the rehydration solution was prepared as follows: $29.5 \mu \mathrm{l}$ of $1 \times$ rehydration buffer, $0.7 \mu \mathrm{l}$ of FITC-labelled LF-probe, $2.0 \mu \mathrm{l}$ of forward primer $(10 \mu \mathrm{M}), 2.0 \mu \mathrm{l}$ of biotin-labelled reverse primer $(10 \mu \mathrm{M}), 10.9 \mu \mathrm{l}$ of nuclease-free water, and $2.0 \mu \mathrm{l}$ of P. multocida standard plasmid DNA or total DNA extracted from clinical samples. Then, $47.5 \mu \mathrm{l}$ of the rehydration solution was transfered to the freeze dried reaction pellet and mixed by vortexing or pipetting up and down until the entire pellet had been resuspended. Finally, the reaction was initiated by adding $2.5 \mu \mathrm{l}$ of magnesium acetate. The reaction tube was inserted into a thermostatic water bath and incubated at $38^{\circ} \mathrm{C}$ for $30 \mathrm{~min}$. The detection specificities of the different primer and LF-probe combinations

Table 4 Sensitivities, specificities, kappa values, and positive or negative predictive values of the RPA-LFD and real-time qPCR or culture methods for the detection of $P$. multocida

\begin{tabular}{|c|c|c|c|c|c|c|c|}
\hline & & \multicolumn{3}{|c|}{ Real-time qPCR } & \multicolumn{3}{|l|}{ Culture } \\
\hline & & Pos & Neg & Total & Pos & Neg & Total \\
\hline \multirow[t]{5}{*}{ RPA-LFD } & Pos & 50 & 2 & 52 & 31 & 21 & 52 \\
\hline & Neg & 0 & 43 & 43 & 0 & 43 & 43 \\
\hline & Total & 50 & 45 & 95 & 31 & 64 & 95 \\
\hline & & Sen:100\% & Spe:95.15\% & K:0.958 & Sen:100\% & Spe:67.20\% & K:0.572 \\
\hline & & PPV:96.15\% & NPV:100\% & & PPV:59.62\% & NPV:100\% & \\
\hline
\end{tabular}




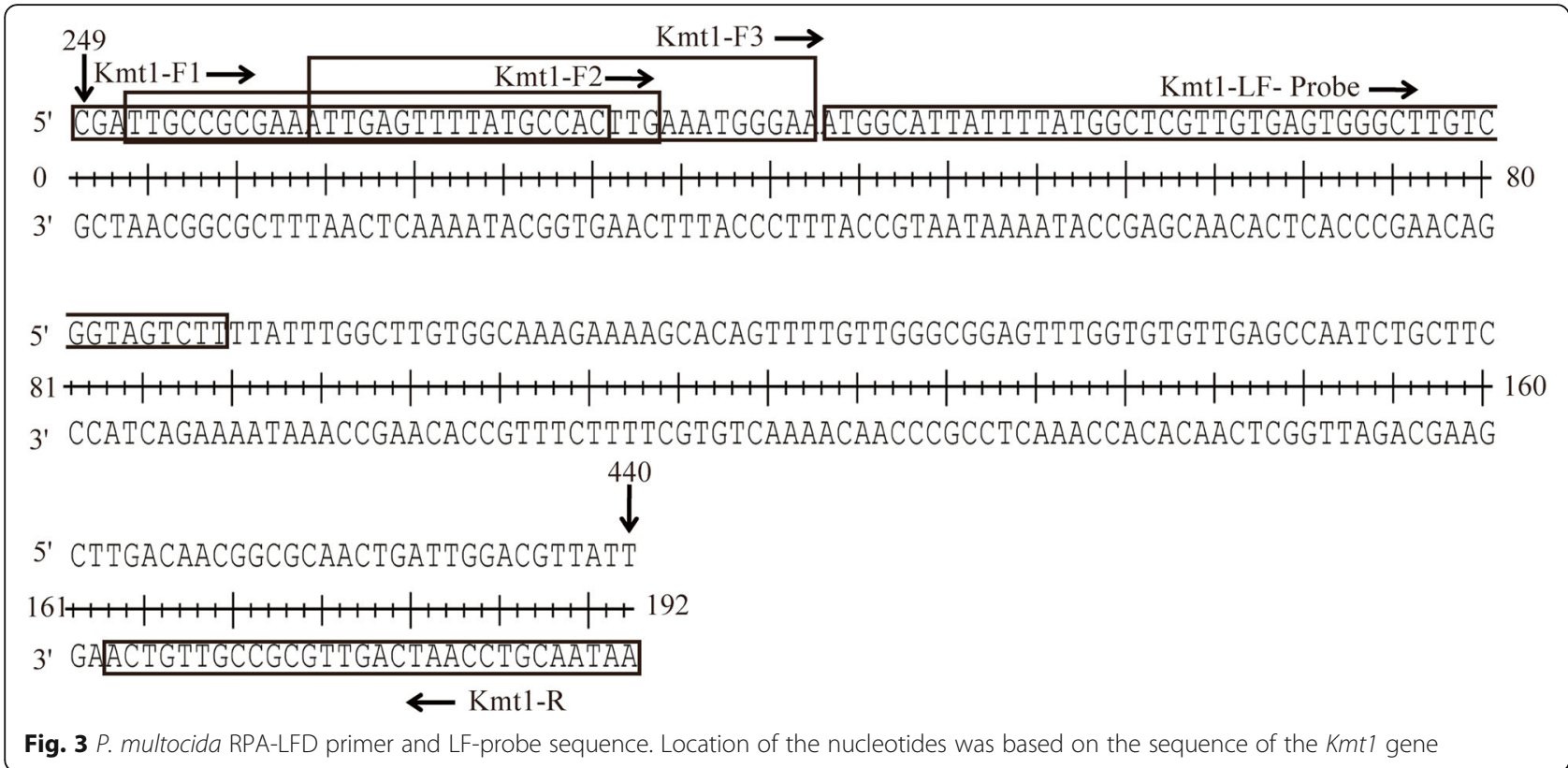

were analysed. The RPA amplification products were purified using a universal UNIQ-10 column DNA purification kit (Sangon Biotech, China) then analysed by $2 \%$ AGE.

To define the optimum RPA reaction temperature, incubation temperatures ranging from $15^{\circ} \mathrm{C}$ to $60^{\circ} \mathrm{C}$ were tested in a thermostatic water bath. Then, incubation times ranging from $1 \mathrm{~min}$ to $40 \mathrm{~min}$ were assessed at the optimal reaction temperature.

\section{Lateral flow dipstick (LFD) assay}

RPA amplification products were assessed by visualization using commercially available LFD (Milenia Genline Hybridetect-1 kits, Giessen, Germany). Dual-labelled RPA products had a $5^{\prime}$ FITC label and a $5^{\prime}$ biotin label on one strand and complementary strand attached to the anti-FITC gold [23]. The reaction products were visualized with dried gold particles conjugated to rabbit anti-FITC antibodies contained in the LFD at the application pad [24]; streptavidin (a biotin-ligand) was immobilized at the detection line. The DNA-gold conjugates were then captured at the biotin-ligand detection line. A control line functionalized with anti-rabbit antibody served as an assay control [23, 24]. Two microlitres of reaction solution were added to a new tube containing $98 \mu \mathrm{l}$ PBST running buffer (PBS containing 0.1\% Tween). Then, the sample pad end of LFD was vertically inserted into the buffer and maintained at room temperature for 5 $\mathrm{min}$. After $5 \mathrm{~min}$, the presence of the RPA product was shown by the development of a coloured test line.

\section{Analytical sensitivity and specificity of RPA-LFD}

Next, positive standard plasmid DNA was constructed for use in RPA-LFD and GPCR (procedures consulting previous studies) using $\mathrm{Pm}-\mathrm{F} 1$ and $\mathrm{Pm}-\mathrm{R}$ primers (Table 5) [25]. The analytical sensitivity of both methods was compared using the standard plasmid DNA (10-fold serial diluted, $6 \times 10^{7}$ to 6 copies/ $\left.\mu \mathrm{l}\right)$. A qPCR assay

Table 5 RPA primers and LF-probe designed in this study

\begin{tabular}{llll}
\hline Name & Sequence(5'-3') & Genome location & Amplification size(bp) \\
\hline Kmt1-F1 & CGATtGCCGCGAATTGAGTTTATGCCAC & $249-278$ & 192 \\
Kmt1-F2 & TTGCCGCGAAATTGATTTTATGCCACTTG & $252-281$ & 189 \\
Kmt1-F3 & ATTGAGTTTATGCCACTTGAAATGGGAA & $262-290$ & 179 \\
Kmt1-R & Biotin-AATAACGTCCAATCAGTTGCGCCGTTGTCA & $411-440$ & 150 \\
Kmt1-LF Probe & FITC-ATGGCATTATTTATGGCTCGTTGTGAGTG & $291-337$ & 241 \\
Pm-F1 & CdSpacer]GCTTGTCGGTAGTT-C3 Spacers & $249-268$ & 113 \\
Pm-F2 & CGATTGCCGCGAATTGAGT & $378-395$ & \\
Pm-R & CAGAGTTGGTGTGTGA & $468-490$ & \\
\hline
\end{tabular}

Abbreviations: dSpacer is an exonuclease site, and C3 Spacers is a polymerase extension blocking site 
for P. multocida was carried out following previously reported procedures [26, 27]. The forward primer $\mathrm{Pm}-\mathrm{F} 2$ and reverse primer $\mathrm{Pm}-\mathrm{R}$ were used to amplify a 113-bp sequence between the 378-490 region of the Kmt1 gene (Table 5). The analytical specificity of RPA-LFD was evaluated using DNA from 4 isolates of P. multocida and 14 reference strains of Pasteurellaceae in addition to other important bacterial pathogens of cattle which cause similar clinical signs (Table 2).

\section{Comparison of the RPA-LFD assay with the real-time qPCR or culture assay using clinical samples}

The RPA-LFD assay for the detection of P. multocida was estimated by performing the assay on 95 clinical samples. The detection of clinical samples was performed in triplicate. The performance of the RPA-LFD assay was compared to that of $\mathrm{qPCR}$ and culture methods. The degree of agreement between the RPA-LFD and GPCR or culture assay results was measured according to the sensitivity, specificity, kappa value, positive predictive value (PPV) and negative predictive value (NPV) of each assay.

\section{Abbreviations}

BRD: Bovine respiratory disease; Ct: Threshold cycle; HS: Haemorrhagic septicaemia; LFD: Lateral flow dipstick; NAAT: Nucleic acid amplification technologies; NPV: Negative predictive value; PCR: Polymerase chain reaction; PPV: Positive predictive value; qPCR: Real-time quantitative PCR; RPA: Recombinase polymerase amplification

\section{Acknowledgements \\ This paper was revised by He Yang, an undergraduate at Emory University and an associate of our lab.}

\section{Funding}

This work was partially supported by grants from the earmarked fund for the Taishan Scholar Project (Hongbin He), the National Natural Science Fund of China (31672556, 31872490), the National Key Research and development program of China (2018YFD0501600) and Shandong province Key Research \& Development program Fund (2018GNC113011). The funder played no role in the design of the study and collection, analysis, and interpretation of data and in writing the manuscript.

\section{Availability of data and materials}

The datasets used and/or analyzed during the current study are available from the corresponding author on reasonable request.

\section{Authors' contributions \\ HMW, HBH and GMZ conceived and designed the experiments. GMZ performed the experiments. HMW analyzed the data. GMZ and $\mathrm{HBH}$ wrote the paper. All the authors read and approved the final manuscript.}

\section{Ethics approval}

Experimental protocols for acquiring cattle clinical samples were performed in strict accordance with the Chinese Regulations of Laboratory Animals (Ministry of Science and Technology of People's Republic of China, 20110108), and the animal study proposal was approved by Shandong Normal University Animal Care and Use Committee. All owners of the farms where nasal swabs and lung tissue samples signed an informed consent before participation in the study.

\section{Consent for publication}

Not applicable

\section{Competing interests}

The authors declare that they have no competing interests.

\section{Publisher's Note}

Springer Nature remains neutral with regard to jurisdictional claims in published maps and institutional affiliations.

Received: 15 January 2019 Accepted: 29 April 2019

Published online: 17 May 2019

\section{References}

1. Wilkie IW, Harper M, Boyce JD, Adler B. Pasteurella multocida: diseases and pathogenesis. Curr Top Microbiol Immunol. 2012;361:1-22.

2. Griffin D. Bovine pasteurellosis and other bacterial infections of the respiratory tract. Vet Clin North Am Food Anim Pract. 2010;26:57-71.

3. Jamali H, Rezagholipour M, Fallah S, Dadrasnia A, Chelliah S, Velappan RD, et al. Prevalence, characterization and antibiotic resistance of Pasteurella multocida isolated from bovine respiratory infection. Vet J. 2014;202:381-3.

4. James A, Macdonald J. Recombinase polymerase amplification: emergence as a critical molecular technology for rapid, low-resource diagnostics. Expert Rev Mol Diagn. 2015;15:1475-89.

5. Zhao G, Hou P, Huan Y, He C, Wang H, He H. Development of a recombinase polymerase amplification combined with a lateral flow dipstick assay for rapid detection of the mycoplasma bovis. BMC Vet Res. 2018;14:412.

6. Piepenburg O, Williams CH, Stemple DL, Armes NA. DNA detection using recombination proteins. PLoS Biol. 2006:4:e204.

7. Wang H, Hou P, Zhao G, Yu L, Gao YW, He H. Development and evaluation of serotype-specific recombinase polymerase amplification combined with lateral flow dipstick assays for the diagnosis of foot-and-mouth disease virus serotype a, O and Asia1. BMC Vet Res. 2018;14:359.

8. Hou P, Wang H, Zhao G, He C, He H. Rapid detection of infectious bovine Rhinotracheitis virus using recombinase polymerase amplification assays. BMC Vet Res. 2017:13:386.

9. Townsend KM, Frost AJ, Lee CW, Papadimitriou JM, Dawkins HJ. Development of PCR assays for species- and type-specific identification of Pasteurella multocida isolates. J Clin Microbiol. 1998;36:1096-100.

10. Murray GM, O'Neill RG, More SJ, McElroy MC, Earley B, Cassidy JP. Evolving views on bovine respiratory disease: an appraisal of selected key pathogens - part 1. Vet J. 2016;217:95-102.

11. Miyoshi S, Hamada H, Miyoshi A, Ito R, Hamaguchi N, Murakami S, et al. Pasteurella multocida pneumonia: zoonotic transmission confirmed by molecular epidemiological analysis. Geriatr Gerontol Int. 2012;12:159-63.

12. Timsit E, Hallewell J, Booker C, Tison N, Amat S, Alexander TW. Prevalence and antimicrobial susceptibility of Mannheimia haemolytica, Pasteurella multocida, and Histophilus somni isolated from the lower respiratory tract of healthy feedlot cattle and those diagnosed with bovine respiratory disease. Vet Microbiol. 2017;208:118-25.

13. Liljander A, Yu M, O'Brien E, Heller M, Nepper JF, Weibel DB, et al. Fieldapplicable recombinase polymerase amplification assay for rapid detection of mycoplasma capricolum subsp. capripneumoniae. J Clin Microbiol. 2015; 53:2810-5.

14. Lillis L, Lehman D, Singhal MC, Cantera J, Singleton J, Labarre P, et al. Noninstrumented incubation of a recombinase polymerase amplification assay for the rapid and sensitive detection of proviral HIV-1 DNA. PLoS One. 2014; 9:e108189.

15. Crannell ZA, Rohrman B, Richards-Kortum R. Equipment-free incubation of recombinase polymerase amplification reactions using body heat. PLoS One. 2014;9:e112146.

16. Yang Y, Qin X, Zhang W, Li Y, Zhang Z. Rapid and specific detection of porcine parvovirus by isothermal recombinase polymerase amplification assays. Mol Cell Probes. 2016;30:300-5.

17. Wang R, Zhang F, Wang L, Qian W, Qian C, Wu J, et al. Instant, visual, and instrument-free method for on-site screening of GTS 40-3-2 soybean based on body-heat triggered recombinase polymerase amplification. Anal Chem. 2017:89:4413-8.

18. Zheng S, Shi J, Wu X, Peng Z, Xin C, Zhang L, et al. Presence of torque Teno sus virus 1 and 2 in porcine circovirus 3-positive pigs. Transbound Emerg Dis. 2018:65:327-30.

19. Zheng S, Wu X, Zhang L, Xin C, Liu Y, Shi J, et al. The occurrence of porcine circovirus 3 without clinical infection signs in Shandong Province. Transbound Emerg Dis. 2017;64:1337-41. 
20. Zhao G, Wang H, Hou P, Xia X, He H. A lateral flow dipstick combined with reverse transcription recombinase polymerase amplification for rapid and visual detection of the bovine respirovirus 3. Mol Cell Probes. 2018;41:22-6.

21. Townsend KM, Boyce JD, Chung JY, Frost AJ, Adler B. Genetic organization of Pasteurella multocida cap loci and development of a multiplex capsular PCR typing system. J Clin Microbiol. 2001;39:924-9.

22. Hou P, Zhao G, Wang H, He C, He H. Rapid detection of bovine viral diarrhea virus using recombinase polymerase amplification combined with lateral flow dipstick assays in bulk milk. Vet Arhiv. 2018;88:627-42.

23. Crannell ZA, Castellanos-Gonzalez A, Irani A, Rohrman B, White AC, RichardsKortum R. Nucleic acid test to diagnose cryptosporidiosis: lab assessment in animal and patient specimens. Anal Chem. 2014;86(5):2565-71.

24. Kersting S, Rausch V, Bier FF, von Nickisch-Rosenegk M. Rapid detection of plasmodium falciparum with isothermal recombinase polymerase amplification and lateral flow analysis. Malar J. 2014;13:99.

25. Zhao G, Wang H, Hou P, He C, He H. Rapid visual detection of Mycobacterium avium subsp. paratuberculosis by recombinase polymerase amplification combined with a lateral flow dipstick. J Vet Sci. 2018;19:242-50.

26. Hou P, Zhao G, He C, Wang H, He H. Biopanning of polypeptides binding to bovine ephemeral fever virus $\mathrm{G} 1$ protein from phage display peptide library. BMC Vet Res. 2018;14:3

27. Settypalli TB, Lamien CE, Spergser J, Lelenta M, Wade A, Gelaye E, et al. Onestep multiplex RT-qPCR assay for the detection of Peste des petits ruminants virus, Capripoxvirus, Pasteurella multocida and mycoplasma capricolum subspecies (ssp.) capripneumoniae. PLoS One. 2016;11:e0153688.

Ready to submit your research? Choose BMC and benefit from:

- fast, convenient online submission

- thorough peer review by experienced researchers in your field

- rapid publication on acceptance

- support for research data, including large and complex data types

- gold Open Access which fosters wider collaboration and increased citations

- maximum visibility for your research: over $100 \mathrm{M}$ website views per year

At $\mathrm{BMC}$, research is always in progress.

Learn more biomedcentral.com/submissions 